\title{
Tests on the centrifugal flotation technique and its use in estimating the prevalence of Toxocara in soil samples from urban and suburban areas of Malaysia.
}

\begin{abstract}
The influence of soil texture (silt, sand and laterite) and flotation solutions (saturated $\mathrm{NaCl}$, sucrose, NaNO3 and $\mathrm{ZnSO} 4$ ) upon the recovery of Toxocara ova from seeded soil samples with the centrifugal flotation technique was investigated. Soil samples of different texture were artificially seeded with Toxocara spp. ova and subjected to a centrifugal flotation technique which used various flotation solutions. The results showed significant $(\mathrm{P}<0.001)$ interactions between the soil types and the flotation solutions. The highest percentage of ova recovery was obtained with silty soil (34.9-100.8\%) with saturated $\mathrm{NaCl}$ as the flotation solution (45.3-100.8\%). A combination of washing of soil samples with $0.1 \%$ Tween 80 , and flotation using saturated $\mathrm{NaCl}$ and a 30 min coverslip recovery period was used to study the prevalence of contamination of soil samples. Forty-six soil samples were collected from up to 24 public parks/playgrounds in urban areas of Petaling Jaya and suburban areas of Serdang. The prevalence of Toxocara species in the urban and suburban areas was $54.5 \%$ and $45.8 \%$ respectively.
\end{abstract}

Keyword: Soil texture; Floatation solutions; Toxocara; Soil samples. 